\title{
LA CONSOLIDACIÓN DEL ESTADO DE FAMILIA, LA IDENTIDAD ESTÁTICA Y DINÁMICA DEL NIÑO Y SU INTEGRACIÓN A SU FAMILIA BIOLÓGICA COMO DERECHOS DEL HIJO EN EL PROCESO DE IMPUGNACIÓN DE PATERNIDAD.
}

\author{
THE FAMILY STATUS, STATIC AND DYNAMIC IDENTITY OF THE \\ CHILD AND HIS INTEGRATION TO ITS BIOLOGICAL FAMILY AS \\ RIGHTS OF THE SON IN THE CHALLENGE OF PATERNITY PROCESS
}

\section{Resumen:}

José Yván Saravia Quispe

La finalidad del presente artículo es analizar los derechos que alcanzan al niño, niña o adolescentecuando seencuentran inmersos en un proceso de impugnación de paternidad, de esta forma, se busca definir el contexto normativo establecido en la irrevocabilidad y caducidad de la negación del reconocimiento de filiación, establecidos en los artículos $395^{\circ}$ y $400^{\circ}$ del Código Civil.

De igual forma, se analizará el derecho a la identidad del niño, tanto en su vertiente estática como en la dinámica y el derecho a ser integrado a su familia biológica, ello con el propósito de comprender con mayor amplitud los derechos invocados y poder efectuar una correcta ponderación ante una evidente colisión de principios; buscando como respuesta lo que más beneficie a la niña, niño o adolescente.

Palabras clave: estado de familia, identidad estática, identidad dinámica, integración a la familia biológica, impugnación de paternidad, caducidad, irrevocabilidad, control difuso, ponderación.

\section{Abstract:}

The purpose of this article is to analyze the rights that reach the child or adolescent when they are immersed in a process of challenge of paternity, in this way, seeks to define the regulatory context established in the irrevocability and expiration of the denial of recognition of filiation, established in articles $395^{\circ}$ and $400^{\circ}$ of the civil code.

Likewise, the right to the child's identity will be analyzed, both in its static aspect and in the dynamics and the right to be integrated to its biological family, with the

Juez Especializado de Familia de la Corte Superior de Justicia de Lima Este. Ex Fiscal Adjunto Provincial de Familia del Distrito Fiscal de Amazonas. Ex Fiscal Adjunto Provincial en lo Civil del Distrito Fiscal de Lima. Maestría en Derecho Civil y Comercial en la Universidad Nacional Federico Villarreal. Doctorado en Derecho en la misma casa superior de estudios. Especialista en Derecho de Familia y Género de la Universidad de Jaén - España. 
purpose of understanding with greater amplitude the invoked rights and being able to make a correct weighing before an evident collision of principles; searching in response what most benefits the child or adolescent.

Key words: family status, static identity, dynamic identity, integration to the biological family, impugnation of paternity, expiration, irrevocability, diffuse control, weighting.

\section{INTRODUCIÓN}

Las reiteradas jurisprudencias de la Corte Suprema respecto al control difuso para inaplicar los artículos $395^{\circ}$ y $400^{\circ}$ del Código Civil, respecto a la irrevocabilidad del reconocimiento de la filiación y plazo de caducidad para negar el reconocimiento, han hecho presumir que dichos artículos per se son inconstitucionales; sin embargo, las últimas consultas y casaciones han empezado a analizar la finalidad de estos dispositivos legales y qué derechos del niño protegen.

Asimismo, si bien en un inicio se consideraba que bastaba la prueba de ADN para excluir del acta de nacimiento al padre legal, actualmente se viene sosteniendo que el derecho a la identidad del niño no es solo la biológica, sino que debe tenerse en cuenta la identidad dinámica, por lo tanto, no se puede descartar de plano que la irrevocabilidad del reconocimiento y el plazo de caducidad para negarlo, vulneren algún derecho del niño; en todo caso ante una colisión de derechos se debe analizar el derecho a la identidad, pero en sus dos vertientes tanto estática como dinámica.

Otro punto importante es el análisis que hace la Corte Suprema respecto a lograr la identificación del padre biológico dentro del proceso de impugnación de paternidad, señalando que excluir al padre legal no garantiza el derecho al niño a ser integrado a su familia biológica; consecuentemente, que se descarte toda referencia a la paternidad del acta de nacimiento, no tendría efectos positivos, por el contrario, en realidad el niño no puede acceder a la verdad sobre su origen biológico.

Como se puede apreciar dentro del proceso de impugnación de paternidad se entrelazan una serie de derechos del niño, niña y adolescente que el Juez deberá tener en cuenta al momento de emitir un pronunciamiento y por lo tanto es necesario conocer cada uno de ellos y cómo es aplicable en cada caso en concreto. 


\section{EL DERECHO A LA CONSOLIDACIÓN DEL ESTADO DE FAMILIA ESTABLECIDO EN EL CÓDIGO CIVIL Y LA CONSTITUCIÓN.}

Según Cornejo Chávez (1999) "el reconocimiento es el acto jurídico por el que una persona manifiesta su paternidad o maternidad extramatrimonial respecto de otra; asimismo, los caracteres del reconocimiento, según el citado autor, son universal, formal, facultativo, personal, individual, puro e irrevocable". (p.111)

Ante este reconocimiento, nuestro legislador ha previsto una serie de restricciones a las posibilidades de negación del acto de reconocimiento de hijo extramatrimonial, todas las cuales buscan limitar la posibilidad de impugnación del vínculo paterno-filial ya formado:

- El artículo $395^{\circ}$ del Código Civil, que establece que el reconocimiento es irrevocable.

- El artículo 399 del Código Civil, que establece que el reconocimiento no puede ser negado por el padre o por la madre que intervinieron en él.

- El artículo $400^{\circ}$ del Código Civil, que establece un plazo de caducidad de noventa días para negar el reconocimiento, contados a partir del momento en que aquel se celebró o en que se tuvo conocimiento del mismo.

Para ingresar al fondo del debate planteado debemos de conocer cuales fueron las razones por la que nuestros legisladores incorporaron estas restricciones en el código civil de 1984, sobre la irrevocabilidad del reconocimiento y el plazo para negarlo.

Señala Cornejo Chávez (1999) que el legislador, en el caso del establecimiento de un plazo perentorio, persigue la finalidad de consolidar un estado de familia en aras de la estabilidad, señalándose que: "La caducidad de las acciones de estado tiende a lograr la consolidación del estado de familia de que se goza, en función de un imperativo de estabilidad" (p. 111)

Para Carlos Cárdenas Quiroz (1999), “el Código Civil contiene normas procesales, de definiciones procesales, trámites, plazos, como el caso del artículo $400^{\circ}$ del Código Civil que incluye en la lista de normas con regulaciones procesales" (p.135). Por lo tanto, el artículo citado contiene 
una norma jurídica regulativa con una regla procesal que califica como permitida la realización de una acción negatoria de paternidad, pero en un plazo específico de caducidad de noventa días, que se computa a partir del momento que se tuvo conocimiento del acto.

En este sentido, estando que la acción impugnatoria cuenta con un plazo de caducidad establecido en el artículo $400^{\circ}$ de la norma sustantiva y en interpretación sistemática con los artículos $2003^{\circ}$ y $2007^{\circ}$ del mismo cuerpo legal, que establece que dicho plazo extingue la acción y el derecho transcurrido el último día del plazo; en consecuencia, la demanda debe ser interpuesta antes del vencimiento del plazo de noventa días de conocido el acto de reconocimiento, para no incurrir en la causal de improcedencia prevista en el artículo 427ํㅡㄹ numeral 3 del Código Procesal Civil en razón de la caducidad.

De igual forma, el acto de reconocimiento provoca, entre otras cosas, que el artículo $395^{\circ}$ de nuestro Código Civil disponga que "el reconocimiento no admite modalidad y es irrevocable"; en efecto, conforme a lo descrito líneas arriba una de las característica del reconocimiento en su irrevocabilidad, a lo señalado por Cornejo Chávez (1999) "por su carácter declarativo o equiparable a la confesión" (p. 111); y también a razón "a las consecuencias que este acto produce no solo en el hijo reconocido (ya sea en el plano material, por las relaciones afectivas que normalmente acompañan a la filiación, como en el jurídico, por el sistema de derecho prevé a favor del niño), sino sobre el propio padre, la familia y la sociedad que exigen que el legislador dote a este acto de características particularmente estrictas para quien lo celebra", conforme se establecío en el Voto de la magistrada Rodríguez Chávez en la Consulta № 3873-2014-San Martín.

Es así que la intervención del legislador contenida en las normas limitando la acción, persigue entonces, la consecución de una finalidad de protección y consolidación del estado de familia, la misma que goza de protección constitucional en el artículo $4^{\mathrm{o}}$ de la Constitución Política del Estado, norma que protege la institución jurídica de familia, como instituto natural y fundamental de la sociedad: "La comunidad y el Estado protegen especialmente al niño, al adolescente, a la madre y al anciano en situación de abandono. También protegen a la familia y promueven el matrimonio. Reconocen a estos últimos como institutos naturales y fundamentales de la sociedad"; que a decir de Plácido Vilcachagua (2005) "el primer deber constitucional que dimana del artículo $4^{\underline{0}}$ para los poderes públicos es el de proteger jurídicamente a la familia constitucional" (p.333-334), constituyendo la familia elemento natural y fundamental de la sociedad gozando de especial protección social y estatal. 
De igual forma, se encuentra tutelada en el derecho internacional de los derechos humanos, específicamente en el artículo 17.1 de la Convención Americana de Derechos Humanos que prescribe que: "La familia es el elemento natural y fundamental de la sociedad y debe ser protegida por la sociedad y el Estado."

Igualmente, lo tiene establecido el artículo 23.2 del Pacto Internacional de Derechos Civiles y Políticos; el artículo 25 de la Declaración Universal de los Derechos Humanos, que establece el derecho de toda persona al nivel adecuado de vida que le asegure a ella y a su familia la salud y el bienestar; el artículo 10.1 del Pacto Internacional de Derechos Económicos, Sociales y Culturales establece la obligación del Estado de brindar a la familia la más amplia protección y asistencia posible para su constitución y mientras sea responsable del cuidado y educación de los hijos a su cargo.

Asimismo, los artículos en análisis regulan una acción de estado. Zanoni (2002) señala que debe entenderse por estado: "la particular atribución a la persona, efectuada por el ordenamiento jurídico, como sujeto de relaciones jurídicas familiares"(p. 90); siendo la ratio legis del código sustantivo la protección al derecho del estado constante de familia, que se hace mucho más vigente en la estructuras de las familias actuales, que pueden estar conformadas por vínculos socioafectivos y no solo sanguíneos, como por ejemplo las denominadas "familias ensambladas", o familias reconstituidas o familias mixtas; conforme lo establecido el Tribunal Constitucional en la Sentencia № 9332-2006-AA.

Asimismo, en el Código Civil de 1984 es posible advertir que la posesión de estado está presente tanto en la institución familiar de la filiación matrimonial como extramatrimonial; por ejemplo, el artículo $375^{\circ}$, admite como medio probatorio de la filiación matrimonial, a la sentencia recaída en juicio en que se haya demostrado la posesión constante de estado de hijo, cuando falta partida de nacimiento del hijo matrimonial de los padres. De igual forma, el artículo $376^{\circ}$, prevé que es inimpugnable la filiación matrimonial cuando se reúnan a favor de la filiación matrimonial la posesión constante del estado; y en aplicación del artículo 402, inciso 2), además de la prueba biológica, permite declarar la filiación extramatrimonial, si el hijo que se halle o se hubiese hallado hasta un año antes de la demanda en la posesión constante de hijo extramatrimonial, comprobado por actos directos del padre o su familia. Esto significa, como lo precisa Mudarra Banto (2016), que "nuestro derecho familiar peruano admite que la paternidad puede basar en un vínculo biológico, en otros casos, también puede sustentarse en la posesión de estado" (p. 62). 
En este sentido, las disposiciones legales, en principio no se encuentra afectadas con vicios de inconstitucionalidad. Detrás de las reglas descritas no existe un mero capricho del legislador por restringir la libertad del reconociente de desdecirse o retractarse posteriormente de su voluntad inicial, sino una meditada ponderación del legislador sobre el impacto que la reiteración de este tipo de circunstancias tendría en el niño, la familia y la sociedad, porque maximiza la protección del instituto de la familia en el sentido de pertenencia de una persona menor de edad en el núcleo familiar; consecuentemente por si solo los articulados normativos no son inconstitucionales debiendo ponderarse en el caso en concreto si existen otros derechos supra que serían más beneficiosos para su interés superior.

\section{EL DERECHO A LA IDENTIDAD ESTÁTICA Y DINÁMICA DEL NIÑO O NIÑA.}

Si bien, la justificación del legislador tiene sustento en un principio constitucional tan importante como la protección y consolidación del estado de familia, también es verdad que en ese momento no se analizó el principio jurídico de la identidad del niño, quizás porque no se tenía regulado como medio probatorio una científica y eficaz como la del ADN.

No obstante, en la actualidad en el marco de la evolución de los derechos humanos entre ellos los del niño, niña y adolescente se ha visto que la protección a la familia como principio constitucional colisionaría con el derecho a la identidad de la persona menor de edad y a ser integrado a su familia biológica, el mismo que tiene sustento en la Convención sobre los derechos del niño y en nuestra Constitución Política del Estado.

Es así, que a la llegada de la prueba científica de ADN es que se otorga una gran importancia al derecho a la identidad en su faz estática que como señala Ortiz de Rosas (2005) "está representada en el origen genético biológico de la persona". (p. 1) Precisando Rivera (1993) que "el derecho a la identidad está comprometido, por lógica consecuencia, con la dignidad personal". (p. 118)

Asimismo, Nora Lloveras citada por Varsi Rospigliosi considera que "la identidad biológica implica el derecho a conocer la fuente de donde proviene la vida, la dotación cromosómica y genética particular, así como los trasmisores de ella - los progenitores o padres- y el entorno del medio en que se expresan los genes, lo cual importa la definición del contexto histórico y cultural del nacimiento o aparición de la persona en el mundo externo y social". (p. 446) 
Por su parte, la Convención sobre los derechos del niño en el artículo 7.1 consagra el derecho de los menores a ser inscritos inmediatamente después de su nacimiento, derecho a un nombre y en la medida de lo posible a conocer a sus padres y ser cuidado por ellos; el artículo 7.2 de la misma Convención obliga a los Estados Partes a velar por la aplicación de estos derechos de conformidad con la legislación nacional y obligaciones contraídas en virtud de los instrumentos internacionales; el artículo 8.1 de la Convención establece el compromiso de los Estados de respetar el derecho del menor a preservar su identidad, incluidos la nacionalidad, nombre y relaciones familiares; y en el artículo 8.2 se establece la obligación de prestar asistencia y protección apropiadas con miras a restablecer rápidamente la identidad cuando el menor es privado ilegalmente de algunos de los elementos de su identidad; coincidiendo con el artículo $6^{\circ}$ de la Declaración de los derechos del niño, contempla el derecho de los menores de edad, al pleno y armonioso desarrollo de su personalidad, y que siempre que sea posible deberá crecer al amparo y bajo la responsabilidad de sus padres.

No obstante, en la actualidad la Jurisprudencia ha identificado que el derecho a la identidad no solo tiene un componente estático o biológico, sino que también cuenta con un componente dinámico y los dos tipos constituyen una unidad inescindible. El primero es el resultado de una información genética que permite identificar biológicamente a cada ser humano sin el riesgo de confundirlo con otro. Esta vertiente de la identidad se complementa, necesariamente, con un plexo de atributos, características y rasgos de la personalidad; estos datos, contrariamente a los biológicos, pueden variar en el tiempo. Por ello, este conjunto de atributos de la personalidad constituye el elemento dinámico de la identidad.

En este sentido, si bien el niño, niña y adolescente, conforme al artículo $6^{\circ}$ del Código de los Niños y Adolescentes tienen derecho a su identidad biológica, a conocer a sus padres y llevar sus apellidos; también el mismo artículo señala que tiene derecho al desarrollo integral de su personalidad, ello dentro del marco de su identidad, que no es otra cosa que su identidad dinámica, siendo un principio contemplado en el numeral 1 del artículo 2 de la Constitución Política del Perú.

Este principio del desarrollo integral de la personalidad se constituye a partir del derecho a la libertad, que permite que cada ser humano decida sobre su propia vida y desarrolle su personalidad en una dirección, según una determinada escala de valores; es en virtud de la libertad que cada cual puede escribir su biografía y perfilar su identidad. 
Consecuentemente, es en base a la libertad y el libre desarrollo de la personalidad que se sustenta jurídicamente la identidad dinámica en el derecho. En este sentido, cabe sostener que la noción de identidad personal es integral, comprende no sólo los datos biológicos estáticos sino, además, aquellos que determinan la personalidad dinámica del sujeto.

En esta vertiente dinámica también se puede observar la posesión de estado paterno filial; es decir, si bien la paternidad se puede basar en un vínculo biológico, también se puede sustentar en la posesión de estado padre e hijo. Asimismo, Aguilar Llanos (2013), nos habla de la verdad socioafectiva, señalando que "el padre social se trata de aquella persona que no siendo padre biológico, si lo es desde el punto de vista legal y se comporta como un verdadero padre, cuida como tal a los hijos, asume todas las responsabilidades propias de un padre, estableciendo una relación beneficiosa para el hijo o hija." (p.13)

Este derecho a la identidad dinámica nos muestra al reconocimiento en su característica de irrevocabilidad ante una posición de estado como vínculo social de filiación; en este sentido, la identidad biológica es importante pero no es absoluta; muchas controversias se sustentarán en la verdad afectiva y en la posesión de estado paterno filial y no solo en los lazos de sangre; no pudiendo descartarse de plano los artículos establecidos en el Código Civil, porque el derecho a la identidad del niño, consagrada en la Constitución y la Convención sobre los derechos del niño, no solo debe analizarse desde su vertiente estática sino también desde la dinámica.

\section{LA ACREDITACIÓN EN JUICIO DE LA IDENTIDAD DINÁMICA EN EL PROCESO DE IMPUGNACIÓN DE PATERNIDAD.}

Cuando se tiene una pretensión de impugnación de paternidad se debe partir en que los artículos $395^{\circ}$ y $400^{\circ}$ del código civil son constitucionales y que su finalidad es proteger a la familia y al ser el control constitucional excepcional debe existir una justificación razonable que haga posible inaplicar tales artículos.

Es así que al colisionar el principio de identidad no basta justificarla solo en la identidad biológica, porque si no estaríamos dejando vulnerable el derecho al libre desarrollo de su personalidad del niño, niña y adolescente, por lo que corresponde que la judicatura también analice su identidad dinámica.

Ahora bien, a diferencia de la identidad biológica que se acreditará con una prueba científica de ADN, la acreditación de la identidad dinámica es más 
compleja porque es un elemento subjetivo, para ello es necesario que las partes procesales o de oficio por el magistrado se incorpore como medio de prueba un informe del equipo interdisciplinario del poder judicial; asimismo, se cumpla con lo establecido en el artículo $85^{\circ}$ del código de los niños y adolescentes, es decir escuchar la opinión del niño y tomar en cuenta la del adolescente.

Cada caso planteado como pretensión en un proceso de impugnación de paternidad resulta diferente a otro; por lo tanto, no se puede generalizar que solo se resolverá la litis con la acreditación de los padres biológicos, sino que existirán casos en que el niño, niña o adolescente haya desarrollado dentro de su identidad una historia familiar en donde identifique como su padre aquel que lo ha reconocido y esa realidad es parte de su derecho al libre desarrollo de su personalidad.

Algunos críticos a esta teoría refieren que el niño, niña y adolescente pueden ser manipulados para que pueda referir o manifestar una historia que en la realidad no sucede, pero para ello está el equipo interdisciplinario que podrá establecer si lo relatado por el infante es fabulado o coherente, asimismo, se puede incorporar testimoniales de su entorno familiar y social para poder acreditar la identidad dinámica.

Asimismo, siempre existirán casos complejos en donde el niño, niña y adolescente ha desarrollado su identidad dinámica, como los hijos reconocidos dentro del matrimonio y que han sido formados dentro del hogar conyugal, arraigados a la familia paterna legal y que luego de muchos años por alguna circunstancia se le informa que su identidad biológica es otra, no pudiendo borrar del niño todo aquello que es parte de su posesión constante de estado padre e hijo y de familia; en esos supuestos, para resolver la controversia, no bastará la prueba biológica de ADN.

De igual forma, habrán casos en los que se podrá resolver la controversia sin mayor inconveniente probatorio en el que primará la realidad biológica, como aquellos en los que el menor de edad no ha desarrollado su identidad familiar con el padre legal, sea por abandono de éste, por motivos de violencia $\mathrm{u}$ otros; asimismo, aquellos que a pesar de que han desarrollado afinidad parental con el padre legal también conocen su origen biológico y éste ha desarrollado afinidad paterno filial con su progenitor y puede ser superado con ayuda profesional especializada. De ahí la importancia de lo señalado por la Corte Suprema cuando indica que dentro del proceso de impugnación de paternidad de un hijo se debe identificar al supuesto padre biológico e incorporarlo como litisconsorte, de esta forma respetando el derecho de defensa se podrá establecer la real identidad del niño al momento de sentenciar. 


\section{DERECHO A SER INTEGRADO A SU FAMILIA BIOLÓGICA Y EL DERECHO A LA INVESTIGACIÓN DE LA PATERNIDAD.}

Otro supuesto que se presenta en los procesos de impugnación de paternidad es que usualmente solo intervienen en la litis la madre y el padre legal, sustentando este último que biológicamente no es el progenitor; sin embargo, no se ha identificado al padre biológico. En estos casos, ha sido usual que las sentencias excluyan la paternidad, pero ello ha generado que los niños, niñas adolescentes no cuenten con su identidad biológica absoluta, es decir, no se ha incluido la identidad del padre biológico, señalando una parte de la doctrina y la jurisprudencia, a la que me aúno, que no se está cumpliendo con el derecho a la integración del niño a su familia biológica, porque el excluir la única identidad que contaba no basta para cumplir con este derecho; de ahí la importancia de replantear la interpretación de este derecho en aplicación a los procesos de impugnación de paternidad.

El derecho a que el niño, niña o adolescente sea integrado a su familia biológica es un derecho importante para la persona menor de edad, porque busca lograr una identidad plena. Para que se cumpla este derecho tiene que excluir al progenitor legal, pero a su vez se deberá incluir al padre biológico.

Es así como toma relevancia el Voto de la magistrada Rodríguez Chávez en la Consulta № 3873-2014-San Martín, cuando señala que: "se evidencia que en los hechos el niño o niña involucrado en la controversia en realidad no puede acceder a la verdad sobre su origen biológico, pues la decisión jurisdiccional que declara en la tinta la urgencia de tutelar su derecho a conocer su origen, únicamente se limita a descartar la filiación que hasta ese momento tiene, pero no proporciona nada en reemplazo de esta afectación. ¿Se satisface, entonces, el derecho a la identidad del menor? No, ya que el padre que formalmente éste tiene ya no es tal (se elimina del acta de nacimiento la paternidad que hasta el momento existía), pero en su lugar el juez no llega a responder cuál es, entonces, la filiación que le corresponde. En consecuencia, si la situación de este menor antes del pronunciamiento del órgano jurisdiccional podría ser cuestionable, su situación luego de éste es evidentemente más precaria."

Es por ello, que para que se inaplique los artículo $395^{\circ}$ y $400^{\circ}$ del Código Civil, no basta con excluir al padre legal sino efectuar una investigación de filiación del niño para determinar en el mismo proceso al padre biológico; siendo importancia la participación del juez como director del proceso en la búsqueda entre los medios probatorios sobre todo en la declaración de las partes y testigos de advertir al supuesto padre biológico, debiendo 
incorporarlo al proceso como litisconsorte necesario en cualquier etapa del proceso y con el mismo sistema de prueba de ADN determinar la verdadera identidad estática de la persona menor de edad, para considerar la declaración judicial de paternidad del progenitor biológico en la sentencia.

Veamos que nos dice al respecto la Corte Interamericana de Derechos Humanos en la sentencia del caso Gelman vs Uruguay, en su fundamento 123: "prevalece el derecho de la familia de educar a los niños que biológicamente traen a la vida, y que cuenta con un dato muy fuerte con base científica, como es la herencia genética de las experiencias culturales acumuladas por las generaciones precedentes, ante lo cual la vía normal de formación de la identidad resulta ser la familia biológica."

Ello vamos a interpretarlo con lo establecido en el artículo 8.2 de la Convención sobre los derechos del niño que establece: "la obligación de prestar asistencia y protección apropiadas con miras a restablecer rápidamente la identidad cuando el menor es privado ilegalmente de algunos de los elementos de su identidad.

En este sentido, si bien el conocer que el padre legal no es el progenitor biológico, no se puede dejar libre el derecho para que se haga valer la investigación de filiación en otro proceso, porque la convención en el artículo señalado nos dice que el restablecimiento de la identidad del niño debe ser rápidamente y tiene su sustento en el principio de su interés superior.

Sobre el derecho a la investigación de la paternidad Varsi Rospigliosi refiere que: "su reconocimiento en el derecho comparado es uniforme y cada vez va teniendo mayor trascendencia. La ley forja el derecho de toda persona de contar jurídicamente con un padre y una madre. A pesar de que la investigación del nexo filial está amparada en normas especiales como el Código Civil y Código de los niños y adolescentes (y en algunos países en el Código de familia), su reconocimiento constitucional e imprescindible, pues fortalece el principio de protección de la familia." (p. 447-448)

Al ser considerado la investigación de paternidad filiatoria un derecho constitucional y convencional es perfectamente posible en aras del interés superior del niño, la acumulación de pretensión a la impugnación de paternidad la filiación extramatrimonial, con la finalidad de que se determine la real identidad biológica del niño, porque el juez no puede sentenciar determinando solo una parte del derecho a la integración a su familia biológica con la sola exclusión del padre legal, sino, como ya hemos referido, la inclusión de su padre biológico, solo así se estaría cumpliendo con el derecho invocado. 
Al respecto en la Casación № 1622-2015-Arequipa, se ha establecido: "...el hecho que se declare la no paternidad ordenando que se descarte toda referencia a la paternidad del acta de nacimiento, no tendría efectos positivos, por el contrario, la apreciación de las consecuencias concretas que este tipo de decisiones produce en la realidad evidencia que en los hechos el niño o niña involucrado en la controversia, en realidad no puede acceder a la verdad sobre su origen biológico, pues la decisión jurisdiccional que declara la urgencia de tutelar su derecho a conocer su origen, únicamente se limita a descartar la filiación que hasta ese momento tiene, pero no proporciona nada en reemplazo de esta afectación."

En efecto, a la luz de una interpretación a favor del niño y no de las partes procesales, se puede llegar a la conclusión que una sentencia, so pretexto de proteger la identidad del niño, descarta la única referencia de paternidad que tenía y que fue establecido a la voluntad del firmante o por mandato de la ley, no tiene efectos positivos, porque el niño en ese proceso no accede a su origen biológico y por ende no se cumple con lo señalado por la Corte Interamenticana de Derechos Humanos y mucho menos con lo establecido en el artículo 8.1 de la convención sobre los derechos del niño.

Está teoría se reafirma en la misma Casación cuando refiere que: "No se satisface, entonces, el derecho a la identidad del menor, ya que el padre que formalmente éste tiene ya no es tal (se elimina del acta de nacimiento la paternidad que hasta el momento existía), pero en su lugar el Juez no llega a responder cuál es, entonces, la filiación que le corresponde. En consecuencia, si la situación de este menor antes del pronunciamiento del órgano jurisdiccional podría ser cuestionable, su situación luego de éste es evidentemente más precaria."

Asimismo, hace referencia al rol importante que cumple los artículos $399^{\circ}$ y $400^{\circ}$ del Código Civil, cuando se presentan estos casos al momento de resolver y como se ha venido señalando, la Corte Suprema de la República en esta casación precisa que estas disposiciones legales son "una clara limitación para el ejercicio de la impugnación del reconocimiento de un hijo extramatrimonial y que a su vez, no resultarían opuestos al derecho a la identidad cuando en el proceso no se logre identificar al verdadero padre biológico y simplemente se opte por excluir el apellido del padre que lo reconoció". Contrario sensu, cuando se ha logrado identificar plenamente el real origen biológico, es decir establecer quien es el padre biológico, la aplicación de las normas establecidas en los artículos $400^{\circ}$ y $395^{\circ}$ de la norma sustantiva si resultarían opuestas al derecho a la identidad de una persona y se podría inaplicar los artículos señalados. 


\section{EL CONTROL DIFUSO COMO EXCEPCIONALIDAD Y LA COLISIÓN DE DERECHOS EN EL PROCESO DE IMPUGNACIÓN DE PATERNIDAD.}

Como se puede apreciar todos los derechos invocados tienen sustento constitucional, pero en el caso en concreto pueden colisionar; ante ello, se ha optado por acudir a la técnica de ponderación de principios mediante el test de proporcionalidad aplicando el control difuso; sin embargo, debe tenerse en cuenta que el control constitucional es excepcional y no puede aplicarse como regla a todos los casos sino debe analizarse en el caso en concreto.

Establecer lo que es más beneficioso para el niño, niña o adolescente nos lleva por el cauce de la afectación de los derechos del niño y de las partes procesales. En la lucha de intereses uno de los derechos debe ceder porque dos derechos no pueden preexistir frente a una misma situación.

En el caso en concreto, en los procesos de impugnación de paternidad se ha establecido un plazo de caducidad en el artículo $400^{\circ}$ del Código Civil, y pese a estar en un código sustantivo es un dispositivo adjetivo y por lo tanto tiene naturaleza imperativa; más aún si entendemos que el legislador pretende proteger el derecho a la consolidación del estado de familia del niño.

No obstante, como se ha señalado no se admite a discusión que las personas menores de edad, detentan un derecho fundamental a la identidad biológica y dinámica, así como a conocer y desarrollarse con su familia natural o biológica, conforme lo establece el artículo IX del Título Preliminar del Código de los Niños y Adolescentes que establece el Principio del Interés Superior del Niño.

Por lo que, si bien en abstracto la norma contenida en el artículo $400^{\circ}$ del Código Civil es constitucional, ello no descarta que la misma norma en concreto, por las particularidades y circunstancias anotadas, presente incompatibilidad con los derechos fundamentales reconocidos constitucionalmente; por lo que corresponde acudir a la técnica de ponderación de derechos que implica. Al respecto, Prieto Sánchez (2010) señala que: "una exigencia de proporcionalidad que implica establecer un orden de preferencia relativo al caso concreto(...); se trata, por tanto, de esa jerarquía móvil que no conduce a la declaración de invalidez de uno de los bienes o valores en conflicto, ni a la formulación de ellos como excepción permanente frente al otro, sino a la preservación abstracta de ambos, por más que inevitablemente ante cada caso de conflicto sea preciso reconocer primacía a uno u otro"(p. 96-97). 
Es importante destacar que en un Estado Constitucional de Derecho con supremacía de la norma constitucional, el ejercicio del control difuso constituye un deber constitucional de los jueces, máxime que el segundo párrafo del artículo $138^{\circ}$ de la Constitución Política del Perú manda que: "En todo proceso, de existir incompatibilidad entre una norma constitucional y una norma legal, los jueces prefieren la primera" La norma constitucional citada guarda perfecta armonía con lo previsto en el artículo 51 de la Carta Magna que dispone: "La Constitución prevalece sobre toda norma legal; la ley, sobre las normas de inferior jerarquía, y así sucesivamente".

No obstante, es pertinente anotar que se presume la validez constitucional de las leyes, que además son obligatorias conforme lo prevé el artículo $109^{\circ}$ de la Constitución Política del Estado, que gozan de legitimidad en tanto hayan sido promulgadas conforme al procedimiento previsto en la Constitución; significado que el uso del control difuso debe ser "excepcional" -aplicándose a los casos de conflicto de normas y para efectos de preservar la primacía de las normas constitucionales; debiendo suponer a priori que la norma no viene viciada de ilegitimidad.

En ese orden, conforme lo señala Canosa Usera (1988) "quien enjuicie la norma esgrimiendo infracción a la jerarquía de la norma constitucional, debe cumplir con la exigencia de demostrar objetivamente la inconstitucionalidad" alegada; en ese mismo sentido, MESÍA Carlos (2004) establece que "por lo que el control difuso procede cuando la inconstitucionalidad de la ley resulte manifiesta y no sea factible encontrar alguna interpretación acorde a la Constitución" (77); por el contrario el uso indiscriminado acarrea inseguridad jurídica en relación a la aplicación de las normas, vulnerando el orden del sistema normativo.

De advertir alguna norma aplicable al caso concreto, que no admita interpretación conforme a la constitución, procederán a realizar el control difuso; debiendo tener sumo cuidado, pues se trata de un proceso gravoso y complejo, en tal sentido, se deben tener presentes las siguientes pautas:
a) Partir de la presunción de constitucionalidad de las normas legales, teniendo presente que, cuando se invoque la inconstitucionalidad de una norma, esta incompatibilidad debe probarse.

b) Realizar un juicio de relevancia, que implique el examen del caso, donde se determine sin lugar a dudas que se trata de la norma legal aplicable, esto es, la norma relevante e indisoluble para la resolución del caso. 
c) Realizar una labor interpretativa exhaustiva, agotando la búsqueda de una interpretación compatible con las normas constitucionales y los derechos fundamentales.

d) Finalmente, sólo cuando no sea posible una interpretación acorde a la Constitución, corresponderá declarar la inaplicabilidad de la norma al caso concreto; en el acto procesal por el cual se resuelve el asunto, esto es en un auto o sentencia (empero se recomienda en ambos casos, que se trate del pronunciamiento sobre el fondo o tema principal del asunto que se resuelve).

Asimismo, se debe tener presente el test de proporcionalidad que incluye, a su vez, tres subprincipios: idoneidad, necesidad y ponderación o proporcionalidad en sentido estricto. El juicio de idoneidad o adecuación, es determinar si la restricción en el derecho resulta pertinente o adecuada a la finalidad que se busca tutelar; en segundo lugar, superado este primer análisis, se debe analizar la medida restrictiva desde la perspectiva de la necesidad; esto supone, verificar si existen medios alternativos al adoptado por el legislador. Se trata del análisis de relación medio-medio, esto es, de una comparación entre medios; el medio elegido por quien está interviniendo en la esfera de un derecho fundamental y el o los hipotéticos medios que hubiera podido adoptar para alcanzar el mismo fin. Finalmente, en un tercer momento y siempre que la medida haya superado con éxito los test o pasos previos, debe proseguirse con el análisis de la ponderación entre principios constitucionales en conflicto. Aquí rige la ley de la ponderación, según la cual "cuanto mayor es el grado de la no satisfacción o de la afectación de un principio, tanto mayor tiene que ser la importancia de la satisfacción del otro. Ello conforme lo establece el Tribunal Constitucional en reiteradas sentencias como la emitida en el Expediente № 579-2018-AA-TC.

En el caso analizado, los artículos que establecen la irrevocabilidad del reconocimiento y el plazo para negarlo, se deben presumir a priori que no vienen viciadas de ilegitimidad, máxime si su finalidad está sustentada en el principio constitucional de protección a la familia, en ese orden quien enjuicie la norma debe cumplir con la exigencia de demostrar objetivamente dicha inconstitucionalidad.

Para ello las partes accionantes invocan el derecho de identidad del niño, también sustentada en la Constitución y la Convención sobre los derechos del niño, generando una colisión de principios constitucionales; sin embargo, como se ha precisado el derecho identidad no solo está conformado por la estática o biológica, sino también por la dinámica, ésta última sustentada en el principio constitucional del libre desarrollo de la personalidad. 
Es así que no resultará sencillo inaplicar los artículos en comentario cuando se demuestre que la identidad filiatoria de una persona menor de edad, en su faceta dinámica, se encuentra en la posesión del estado de hijo o hija del padre legal, asimilando la identidad de la familia y cultura en que vive. También, cabe la posibilidad que dicha identidad dinámica sea arraigada al padre biológico y por lo tanto, se tendrá que inaplicar los artículos; no obstante, cual fuera el hecho, la ponderación tendrá que realizarse en el caso en concreto debiendo la Judicatura necesariamente tener en cuenta en su motivación la identidad estática y dinámica del niño, niña y adolescente.

De igual forma, la ponderación tendrá una conclusión distinta sino se asegura dentro del proceso que el niño se integrará a su familia biológica; es decir, se haya realizado durante el proceso una investigación filiatoria con la finalidad de incluir la paternidad biológica del hijo y garantizar plenamente su derecho de ser integrado a su familia biológica.

Pero debe quedar claro que no todos los casos de impugnación de paternidad concluirán con un control difuso o que la Judicatura solo tendrá en cuenta la prueba de ADN de exclusión del padre legal; ello a razón de que la inaplicación de una norma legal, que se interpreta contraria a la Constitución, constituye una prerrogativa jurisdiccional de última ratio; asimismo, que la colisión de principios constitucionales en los casos de impugnación de paternidad no se resume en el principio de identidad biológica, sino también en los derechos analizados en el presente artículo; asimismo, no bastará excluir de la partida de nacimiento al padre legal sin incluir al padre biológico; debiendo efectuarse forzosamente un test de proporcionalidad en el caso concreto, siempre teniendo en cuenta el interés superior del niño.

\section{CONCLUSIÓN}

- La intervención del legislador contenida en los artículos $395^{\circ}$ y $400^{\circ}$ del Código Civil y que limita la acción, persigue la finalidad de protección y consolidación del estado de familia, la misma que goza de protección constitucional en el artículo $4^{\circ}$ de la Constitución Política del Estado, norma constitucional que protege la institución jurídica de familia.

- En este sentido, las disposiciones legales, en principio no se encuentra afectadas con vicios de inconstitucionalidad. Detrás de las reglas descritas no existe un mero capricho del legislador por restringir la libertad de quien reconoce de desdecirse o retractarse posteriormente 
de su voluntad inicial, sino una meditada ponderación del legislador sobre el impacto que la reiteración de este tipo de circunstancias tendría en el niño, la familia y la sociedad. porque maximiza la protección del instituto de la familia en el sentido de pertenencia de una persona menor de edad en el núcleo familiar.

- En el marco de la evolución de los derechos humanos entre ellos los del niño, niña y adolescente se ha visto que la protección a la familia como principio constitucional colisionaría con el derecho a la identidad de la persona menor de edad y a ser integrado a su familia biológica, el mismo que tiene sustento en la Convención sobre los derechos del niño y en nuestra Constitución Política del Estado.

- No obstante, en la actualidad la Jurisprudencia ha identificado que el derecho a la identidad no solo tiene un componente estático o biológico, sino que también cuenta con un componente dinámico y los dos tipos constituyen una unidad inescindible. El primero es el resultado de una información genética que permite identificar biológicamente a cada ser humano sin el riesgo de confundirlo con otro. Esta vertiente de la identidad se complementa, necesariamente, con un plexo de atributos, características y rasgos de la personalidad; estos datos, contrariamente a los biológicos, pueden variar en el tiempo.

- Este derecho a la identidad dinámica nos muestra al reconocimiento en su característica de irrevocabilidad ante una posición de estado como vínculo social de filiación; en este sentido, la identidad biológica no es absoluta; muchas controversias se sustentarán en la verdad afectiva y en la posesión de estado paterno filial y no solo en los lazos de sangre; no pudiendo descartarse de plano porque es parte del derecho a la identidad del niño consagrada en la Constitución y la Convención sobre los derechos del niño.

- Ahora bien, a diferencia de la identidad biológica que se acreditará con una prueba científica de ADN, la acreditación de la identidad dinámica es más compleja porque es un elemento subjetivo, para ello es necesario que las partes procesales o de oficio por el magistrado se incorpore como medio de prueba un informe del equipo interdisciplinario del poder judicial; asimismo, se cumpla con lo establecido en el artículo $85^{\circ}$ del código de los niños y adolescentes, es decir escuchar la opinión del niño y tomar en cuenta la del adolescente. 
- Asimismo, siempre existirán casos complejos en donde el niño, niña y adolescente ha desarrollado su identidad dinámica, como los hijos reconocidos dentro del matrimonio y que han sido formados dentro del hogar conyugal, arraigados a la familia paterna legal y que luego de muchos años por alguna circunstancia se le informa que su identidad biológica es otra, no pudiendo borrar del niño todo aquello que es parte de su posesión constante de estado padre e hijo y de familia; en esos supuestos, para resolver la controversia, no bastará la prueba biológica de ADN.

- El derecho a que el niño, niña o adolescente sea integrado a su familia biológica es un derecho importante para la persona menor de edad, porque busca lograr una identidad plena. Para que se cumpla este derecho tiene que excluir al progenitor legal, pero a su vez se deberá incluir al padre biológico.

- Es por ello, que para que se inaplique los artículo $395^{\circ}$ y $400^{\circ}$ del código civil, no basta con excluir al padre legal sino efectuar una investigación de filiación del niño para determinar en el mismo proceso al padre biológico; siendo de importancia la participación del juez como director del proceso en la búsqueda entre los medios probatorios sobre todo en la declaración de las partes y testigos de advertir al supuesto padre biológico, debiendo incorporarlo al proceso como litisconsorte necesario en cualquier etapa del proceso y con el mismo sistema de prueba de ADN determinar la verdadera identidad estática de la persona menor de edad, para considerar la declaración judicial de paternidad del progenitor biológico.

- Los artículos que establecen la irrevocabilidad del reconocimiento y el plazo para negarlo, se deben presumir a priori que no vienen viciadas de ilegitimidad, máxime si su finalidad está sustentada en el principio constitucional de protección a la familia, en ese orden quien enjuicie la norma debe cumplir con la exigencia de demostrar objetivamente dicha inconstitucionalidad.

- No todos los casos de impugnación de paternidad concluirán con un control difuso o que la Judicatura solo tendrá en cuenta la prueba de ADN de exclusión del padre legal; ello a razón de que la inaplicación de una norma legal, que se interpreta contraria a la Constitución, constituye una prerrogativa jurisdiccional de última ratio; asimismo, que la colisión de principios constitucionales en los 
casos de impugnación de paternidad no se resume en el principio de identidad biológica, sino que se deberá tener en cuenta todos los derechos precisados en el presente artículo académico.

\section{REFERENCIAS}

Aguilar Llanos B. (2013). La filiación en la jurisprudencia del Tribunal Constitucional, Lima: Gaceta Jurídica.

Atienza, Manuel y Ruiz Manero, Juan (2004). Las Piezas del Derecho, Teoría de los Enunciados Jurídicos, Barcelona: Editorial Ariel.

Cárdenas Quiroz, Carlos (1999). Para Leer el Código Civil, Volumen II, Lima: Fondo Editorial, Pontificia Universidad Católica.

Canosa Usera, Raúl (1998). Interpretación y Fórmula Política, Madrid: Centro de Estudios Constitucionales.

Cornejo Chávez, Héctor (1999). Derecho Familiar Peruano, Lima :Gaceta Jurídica Editores S.R.L., $10^{\circ}$.

Cornejo Chávez, Héctor (1982). Derecho Familiar Peruano, Sociedad Paterno- filial, Lima: Editorial Studium.

Cornejo Chávez, Héctor (Setiembre 1998). Comisión Encargada del Estudio y Revisión del Código Civil, Código Civil, IV, Exposición de Motivos y Comentarios, Derecho de Familia, Compiladora: Delia Revoredo de Debakey. Tercera Edición, Lima Perú.

Fernández Sessarego, Carlos (1992). Derecho a la identidad personal, Buenos Aires: Editorial Astres.

Ferrer Mac-Gregor, Eduardo (2008). La ciencia del derecho procesal constitucional. Estudio en Homenaje a Héctor Fix-Zamudio en sus cincuenta años como investigador del Derecho. Tomo VIII - Procesos Constitucionales Orgánicos. Sánchez Gil, Rubén "La presunción de constitucionalidad", México: Marcial Pons.

Hakansson Nieto, Carlos (2014). El proceso de inconstitucionalidad, una aproximación teórica y jurisprudencial, Lima: Palestra.

Mesía Carlos (2004). Exégesis del Código Procesal Constitucional, Lima: Gaceta Jurídica. Primera Edición. 
Mudarra-Abanto, María (s/f). Criterios para una adecuada admisión y resolución de demandas por negación del reconocimiento.

Ortiz de Rosas, Abel Fleitas. (15 de noviembre, 2005). Derecho a la Identidad. La Ley. Buenos Aires, Año LXIX, №222.

Prieto Sánchez, Luis (2010). El juicio de ponderación constitucional. Principio de Proporcionalidad en el Derecho Contemporáneo, Lima: Palestra.

Plácido Vicachagua, Alex (2005). La familia en la Constitución Peruana. La Constitución Comentada, Análisis artículo por artículo, obra colectiva escrita por 117 destacados juristas del Perú. Director: Walter Gutiérrez, Tomo I, Lima: Editorial Gaceta Jurídica, Primera Edición.

Varsi Rospigliosi, Enrique (s/f). La Investigación de la Paternidad. Tomo IV, Gaceta Jurídica.

Zannoni, Eduardo A. (2002). Derecho Civil, Derecho de Familia, Tomo II, 4ta. Edición Actualizada, Buenos Aires: Editorial Astrea.

Fecha de recepción : : 29 de agosto de 2018

Fecha de aceptación : : 25 de octubre 2018 